\title{
NOTE ON NON-SURVEY INPUT-OUTPUT MODELS FOR MULTICOUNTY REGIONS: COMMENT
}

\author{
G. Andrew Bernat, Jr.*
}

Introduction

Mark Henry's note ${ }^{1}$ in this Review shows that the use of the simple location quotient (SLQ) method of constructing regional and subregional IO models may result in some of the subregional coefficients being larger than the corresponding regional coefficients. He asserts that this is an inconsistency that requires a correction. The proposed correction is to use the largest subregional SLQ for the regional SLQ whenever a subregional SLQ exceeds the regional SLQ (MAXSLQ). The purpose of this comment is to demonstrate that there is in fact no inconsistency in this result. The use of MAXSLQ will thus introduce additional error into the regional model.

The SLQ Method

Following Henry's notation, the SLQ for any sector $i$ is the proportion of total regional employment comprised by employment in sector i divided by the proportion of total national employment comprised by employment in sector i:

(1) $\mathrm{SLQ}_{\mathrm{i}}=\left(\mathrm{E}_{\mathrm{ik}} / \sum^{\mathrm{n}}{ }_{\mathrm{i}=1} \mathrm{E}_{\mathrm{ik}}\right) \div\left(\sum^{\mathrm{m}_{\mathrm{k}=1}} \mathrm{E}_{\mathrm{ik}} /\right.$ $\left.\sum^{\mathrm{n}}{ }_{\mathrm{i}=1} \sum^{\mathrm{m}_{\mathrm{k}=1}} \mathrm{E}_{\mathrm{ik}}\right)$

where $\mathrm{SLQ}_{\mathrm{ik}}$ is the SLQ for sector i in region $\mathrm{k}$, $\mathbf{E}_{\mathrm{ik}}$ is sectoral employment at the regional level, and $n$ and $m$ are the number of sectors and regions, respectively. If the region is to be divided into $\mathrm{k}$ counties the sector i SLQ for the $\mathrm{r}^{\text {th }}$ county is

(2) $\mathrm{SLQ}_{\mathrm{ikr}}=\left(\mathrm{E}_{\mathrm{ikr}} / \Sigma^{\mathrm{n}} \mathrm{i=1}_{\mathrm{ikr}} \mathrm{E}_{\mathrm{ik}}\right) \div\left(\sum_{\mathrm{k}=1}^{\mathrm{m}} \mathrm{E}_{\mathrm{ik}} /\right.$ $\left.\sum_{\mathrm{i}=1} \sum^{\mathrm{m}_{\mathrm{k}=1}} \mathrm{E}_{\mathrm{ik}}\right)$

where $E_{i k r}$ is sectoral employment for the $r^{\text {th }}$ county.

*Virginia Polytechnic Institute and State University, Blacksburg. The author wishes to thank Prof. Thomas Johnson for helpful comments.
Why There Is No Multicounty Problem

As Henry points out, there is no reason for $\mathrm{SLQ}_{\mathrm{ikr}}$ to be less than SLQ $\mathrm{ik}_{\mathrm{ik}}$ This means that the technical coefficients for sector $i$ in the county model will be larger than the corresponding coefficients in the regional model. However, there is no inconsistency in this result because the technical coefficients are proportions and not quantities. In fact, technical coefficients in IO models are averages of proportions. In essence, the coefficient $a_{i j}$ is the average proportion of the total value of the output of sector $j$ which is comprised by purchases from sector $i$. Thus, at the national level some firms in sector $j$ will require more than $a_{i j}$ of sector i's output to produce a unit of output and some less. At the regional and subregional levels the technical coefficients are averages of trade coefficients as well as of production coefficients. In other words, the regional and subregional coefficients represent purchases by firms within the region (subregion) of output of other firms, also within the region (subregion). It would not be at all surprising to find that sectors in some counties in a particular region purchase a higher proportion of their inputs from local sources than do firms in the corresponding sectors of other counties. In such cases some of the county technical coefficients would be greater than the corresponding average, or regional, coefficient, especially if intercounty trade is not great. This is particularly likely to happen if the counties within the region differ widely in size and composition.

Alternatively, the fact that MAXLQ is unnecessary can be demonstrated by noting that the regional technical coefficients $a_{i j}$ are weighted averages of the county coefficients $a_{i j}^{r_{i j}}$ and the intercounty trade coefficients $a_{i j}, s=r$, the weights being each county's share of regional sectoral output. Define the following variables: 
$\mathbf{x}^{\mathbf{j}}=$ total regional output of sector $\mathrm{j}$

$\mathbf{x}_{\mathrm{ij}}=$ total regional purchases of sector i's output by sector $j$

$a_{i j}=x_{i j} / x_{j}=$ the $i j_{t h}$ technical coefficient

$\mathbf{x}_{j}{ }_{j}=$ total output of sector $j$ in county $r$

$\mathbf{x}_{i j}^{s_{j}} \mathbf{r}_{j}=$ purchases by sector $j$, in county $r$, of the output of sector $i$, county $s$

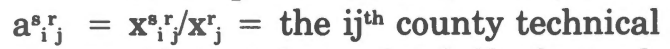
coefficient from the full nk $\times$ nk 'ideal' interregional IO model (Richardson $^{3}$ ).

Purchases by sector $j$ of the output sector $i$ at the regional level are:

$$
\text { (3) } \mathrm{X}_{\mathrm{ij}}=\sum_{\mathrm{s}=1}^{\mathrm{k}} \sum_{\mathrm{r}=1}^{\mathrm{k}} \mathrm{X}_{\mathrm{ij}}^{\mathrm{sr}}=\sum_{\mathrm{s}=1}^{\mathrm{k}} \mathrm{X}_{\mathrm{j}}^{\mathrm{r}_{\mathrm{j}}} \mathrm{a}_{\mathrm{ij}}^{\mathrm{rr}}
$$

The regional level technical coefficient $a_{i j}$ is thus:

$$
\begin{aligned}
& \text { (4) } a_{i j}=x_{i j} / x_{j}
\end{aligned}
$$

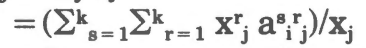

$$
\begin{aligned}
& =\sum_{r=1}^{\mathbf{k}} \delta_{r} a_{i j}^{r_{j}}+\sum_{s=1}^{k_{s=1}} \sum_{r=1}^{k} \delta_{r} a_{i j}^{s} r_{j}
\end{aligned}
$$

where $\delta_{r}$ is county r's share of the total output of sector $\mathrm{j}$ at the regional level. Thus $0 \leqslant \delta_{\mathrm{r}} \leqslant 1$ for all $r$ and $\sum_{r=1}^{k} \delta_{r}=1$. It is obvious that in the limiting case of no intercounty trade $\left(a_{i j}^{8} r_{j}=0\right.$ for all $\mathbf{r} \neq \mathbf{s}$ ) if any technical coefficients are less than the corresponding regional coefficient at least one of the county coefficients must be larger than the regional coefficient. The presence of inter-county trade means that in any particular situation the trade linkages may be large enough that the regional coefficients are greater than any of the county coefficients. However, because there is no a priori reason to believe that this is true, the use of a procedure such as MAXSLQ is unjustified.

\section{Conclusions}

The SLQ method is often used to estimate what can be called regional purchase coefficients. Both Stevens and Trainer ${ }^{4}$ and Park, Mohtadi, and Kubursi ${ }^{2}$ have shown that one of the most important sources of error in regional IO models is the estimation of regional purchase coefficients. As demonstrated in this comment, the use of MAXLQ will introduce additional error into the SLQ estimation procedure and consequently will further degrade the accuracy of regional IO models.

\section{REFERENCES}

${ }^{1}$ Henry, Mark. "A Note on Nonsurvey Input-Output Models for Multicounty Regions," The Review of Regional Studies, 10 (Spring, 1980), pp. 68-71.

${ }^{2}$ Park, Se-Hark, Mohtadi, Malek, and Kubursi, Atif. "Errors in Regional Input-Output Models: Analytical and Simulation Results," Journal of Regional Science, 21 (August, 1981). pp. 321-339

${ }^{3}$ Richardson, Harry W. Input-Output and Regional Economics. London: Weidenfeld and Nicolson (1972)

${ }^{4}$ Stevens, B. H. and Trainer, G. A. "Error Generation in Regional Input-Output Analysis and Its Implications for Nonsurvey Models," Discussion Paper No. 108, Philadelphia: Regional Science Research Institute, (December 1978). 